\title{
INTERPRETATION OF PROBE MEASUREMENTS IN A COLLISIONLESS PLASMA FLOW
}

\author{
Institute of Technical Mechanics \\ of the National Academy of Sciences of Ukraine and the State Space Agency of Ukraine \\ 15 Leshko-Popel St., Dnipro 49005, Ukraine; e-mail: lazuch.dn@ gmail.com
}

The aim of this work is to develop and substantiate a procedure for the characterization of an unperturbed collisionless plasma on the basis of a parametric description of the current-voltage characteristic of a thin cylindrical probe positioned perpendicular to the plasma flow with the use of a priori information on the plasma properties and the experimental conditions. Based on the Vlasov-Poisson kinetic model, the two-dimensional direct problem of probe measurements was studied numerically. The ion and electron currents to a cylinder positioned perpendicular to the plasma flow were calculated as a function of the ion velocity ratio, the degree of plasma nonisothermality, and the ratio of the probe radius to the Debye length. Based on the results of the calculations, the classical approximations of the probe currents were corrected, and the applicability ranges of the approximation of the total current-voltage characteristic of a thin cylindrical probe in a collisionless plasma flow were determined. A procedure was developed for identifying the parameters of an unperturbed plasma based on a comparison of the theoretical approximation of the current-voltage characteristic with the measured data. A priori information on the plasma properties and the experimental conditions is given as limitations to the approximation parameters of the current-voltage characteristic. The effect of probe measurement errors on the identification of the plasma parameters was studied. The results obtained may be used in the diagnostics of a collisionless plasma.

Keywords weakly ionized collisionless plasma flow, cylindrical Langmuir probe, numerical simulation, parametric identification, a priori information.

1. Chung P., Talbot L., Touryan K. Electric Probes in Stationary and Flowing Plasmas (in Russian). Moscow: Mir, 1978. $201 \mathrm{pp}$.

2. Alekseev B. V., Kotelnikov V. A. Probe Method for Plasma Diagnostics (in Russian). Moscow: Energoatomizdat, 1988. $240 \mathrm{pp}$

3. Shuvalov V. A. Simulation of Body-Ionosphere Interaction (in Russian). Kyiv: Naukova Dumka, 1995. 180 pp.

4. Alpert L. A., Gurevich A. V., Pitaevsky L. G. Satellites in a Rarefied Plasma. Moscow: Nauka, 1964. 382 pp.

5. Kotelnikov V. A., Uldanov S. V., Kotelnikov M. V. Transfer Processes in Plasma Wall Layers (in Russian). Moscow: Nauka, 2004. 422 pp.

6. Lazuchenkov D. M. Calculation of an electron-repulsing self-consistent electric field near a cylinder in a rarefied plasma flow (in Russian). Tekhnicheskaya Mekhanika. 2012. No. 4. Pp. 27-35.

7. Lazuchenkov D. M., Lazuchenkov N. M. Simulation of interactions between rarified plasma flow and faired charged conducting cylinder near conducting surface (in Russian). Tekhnicheskaya Mekhanika 2014. No. 2. Pp. 63-72.

8. Mott-Smith H., Langmuir I. The theory of collectors in gaseous discharges. Phys. Rev. 1926. V. 28. No. 5. Pp. 727-763.

9. Latramboise J. G. Theory of Spherical and Cylindrical Langmuir Probes in a Collisionless Maxwellian Plasma at Rest. Report, No. 100. Univ. of Toronto, Institute of Aerospace Studies. 1966. 210 pp.

10. Hoegy W. R., Wharton L. E. Current to a moving cylindrical electrostatic probe. Journal of Applied Physics 1973. V. 44. No. 12. Pp. 5365-5371.

11. Kotelnikov M. V. Current-Voltage Characteristics of a Cylindrical probe in a Collisional and a Collosionless Plasma Flow (in Russian). Teplofizika Vysokikh Temperatur. 2008. No. 4. Pp. 629-632.

12. Moskalenko A. K. On the theory of a cylindrical Probe (in Russian). Kosmicheskie Isledovaniya. 1979. V. 17. No.1. Pp. 51-59.

13. Laframboise J. G., Sonmor L. J. Current collection by probes and electrodes in space magnetoplasma: Review J. Geophys. Research. 1993. V. 98. No. 1. Pp. 337-357.

14. Godard R., Laframboise J. Total current to cylindrical collectors in collisionless plasma flow. Space Science. 1983. V. 31. No. 3. p. 275-283.

15. Kozlov O. V. Electric Probe in Plasma (in Russian). Moscow: Atomizdat, 1969

16. Shuvalov V.A., Pis'mennyi N. I., Lazuchenkov D. N., Kochubei G. S. Probe diagnostics of laboratory and ionospheric rarefied plasma flows. Instruments and Experimental Techniques. 2013. V. 56. No. 4. Pp. 459-467.

17. Shuvalov V. A., Lukeniuk A. A., Pis'mennyi N. I., Kulagin S. N. Probe diagnostics of the near-satellite environment onboard the Sich-2 (in Russian). Kosmichna Nauka i Tehnologia. 2013. V. 19. No. 1. Pp. 1319. 